\title{
Foci report on indigenous Dermacentor reticulatus populations in Belgium and a preliminary study of associated babesiosis pathogens
}

Christel Cochez ${ }^{1 * \#}$, Laetitia Lempereur ${ }^{2 * \#}$, Maxime Madder $^{3,4}$, Edwin Claerebout ${ }^{5}$, Leopold Simons ${ }^{1}$, Nathalie De Wilde ${ }^{5}$, Annick Linden ${ }^{7}$, Claude Saegerman ${ }^{6}$, Paul Heyman $^{1}$, Bertrand Losson $^{2}$

${ }^{1}$ Research Laboratory for Vector Borne Diseases, Queen Astrid Military Hospital, B-1120 Brussels (Belgium).

${ }^{2}$ Laboratory of Parasitology and Parasitic Diseases, Department of Infectious and Parasitic Diseases, Faculty of Veterinary Medicine, University of Liège, B-4000 Liège (Belgium).

${ }^{3}$ Department of Animal Health, Institute of Tropical Medicine, B-2000 Antwerp (Belgium).

${ }^{4}$ Department of Veterinary Tropical Diseases, Faculty of Veterinary Science, University of Pretoria (South Africa).

${ }^{5}$ Laboratory of Parasitology, Faculty of Veterinary Medicine, Ghent University, B-9820 Merelbeke (Belgium).

${ }^{6}$ Research Unit of Epidemiology and Risk Analysis Applied to the Veterinary Sciences (UREAR), Department of Infectious and Parasitic Diseases, Faculty of Veterinary Medicine, University of Liège, B-4000 Liège

(Belgium).

${ }^{7}$ Wildscreen Network, Department of Infectious and Parasitic Diseases, Faculty of Veterinary Medicine, University of Liège, B-4000 Liège (Belgium).

\# both authors contributed equally

*Corresponding authors:

Christel Cochez

Research Laboratory for Vector Borne Diseases

Queen Astrid Military Hospital

Bruynstraat, 1, B-1120 Brussels, Belgium

E-mail: Christel.Cochez@mil.be

Laetitia Lempereur

Laboratory of Parasitology and Parasitic Diseases

Department of Infectious and Parasitic Diseases,

Faculty of Veterinary Medicine, University of Liège

Boulevard de Colonster, 20, B-4000 Liège, Belgium

E-mail: 1.lempereur.1@research.gla.ac.uk 


\begin{abstract}
The occurrence of indigenous clinical cases of canine (Losson et al., 1999) and equine (Mantran et al., 2004) babesiosis in Belgium during the last two decades suggests that the vector of the pathogens responsible for these diseases, Dermacentor reticulatus, could be present in Belgium. Consequently evidence for the presence of this tick species in different locations in Belgium was investigated. Four different locations throughout Belgium were monitored by flagging in 2010 and included the locations where D. reticulatus was found on a dog in 2009 and on two red deer in 2007. Two different tick species were identified, i.e. Ixodes ricinus and D. reticulatus. A total of 282 D. reticulatus adult ticks (98 males, 184 females) were collected from the 4 sites. Ticks were found mainly from early March until the end of May with a peak of activity in April. A Babesia spp. genus-specific PCR test based on the amplification of a 411-452 bp fragment of the 18S rRNA gene was used to investigate the potential presence of Babesia spp. All DNA extracts isolated from the total tick samples yielded negative results. Additional studies to accurately determine the distribution and vectorial capacity of this important tick species in Belgium are warranted.
\end{abstract}

Keywords: Tick-Dermacentor reticulatus-Babesia spp.-Belgium

\title{
Introduction
}

At least 16 tick species, classified to six genera (Argas, Ixodes, Dermacentor, Hyalomma, Amblyomma, Rhipicephalus) and two families (Argasidae and Ixodidae) have been recorded in Belgium (Fain, 1990). However, many of these species were recorded on imported animals or on animals with a history of travel and, consequently, cannot be considered to represent permanent indigenous populations. Ixodes ricinus and Ixodes hexagonus are the two most abundant species in North-Western Europe and of these two species I. ricinus is the most important vector of human disease. The distribution of I. ricinus in Northern Europe is widespread and determined mainly by the presence of habitats with a high level of humidity.

The distribution of Dermacentor reticulatus (marsh tick or ornate cow tick) in Europe is more limited and localised. The geographic range of this species extends -West-East wards- from France and the 
southwest of the United Kingdom to central Asia. Its southern limit is the Mediterranean Sea but here it is restricted to humid, medium altitude areas. Until recently the French-Belgian border was considered to be the northern boundary of the distribution of D. reticulatus in Western Europe (Heile et al., 2006) and within its entire distribution area, the distribution of this tick species is highly focal (Gray et al., 2009). Recently, several reports indicated an expanding geographical distribution of $D$. reticulatus. Indeed, D. reticulatus ticks were collected from the environment during the last decade in The Netherlands (Nijhof et al., 2007) and in different German Länder (Dautel et al., 2006). Evidence for the changing distribution of $D$. reticulatus was also provided by the occurrence of canine babesiosis in new regions in Germany (Heile et al., 2006; Barutzki et al., 2007), Hungary (Sréter et al., 2005), Switzerland (Porchet et al., 2007) and the Netherlands (Nijhof et al., 2007). Several factors could be responsible for the apparent expansion of the distribution area of D. reticulatus: increased deer abundance and the availability of more fallow land as a result of EU agricultural policies and a warming climate could, at least partly, be involved (Lindgren \& Gustafson, 2001).

In Belgium, adults of $D$. reticulatus were found on a dog in Torgny and from an unspecified animal species in Gérouville in 1945 and 1950 respectively (both localities are located in the south of Luxembourg province very close to the French border) (Fain, 1989). However, these historical observations did not provide any information on the origin of the tick or the travel history of the dog. More recently, low numbers of D. reticulatus were reported on dogs in Belgium (Losson et al., 2003). In France D. reticulatus is the most important vector of canine babesiosis (Babesia canis canis) (Martinod \& Gilot ,1991). D. reticulatus can also transmit the protozoans Theileria equi and Babesia caballi of horses (Perez-Eid, 2007) and is also a vector of tick-borne encephalitis virus (TBE), Rickettsia conori (boutonneuse fever) (Hillyard, 1996), Rickettsia slovaca (Raoult et al., 2002), Francisella tularensis (tularemia) and Coxiella burnetii (Q-fever) (Estrada-Pena \& Jongejan ,1999). Borrelia sp. (probably B. burgdorferi) was identified in this tick in Saxony in Eastern Germany (Kahl et al., 1992). Presence of Anaplasma phagocytophilum DNA was recently detected in D.reticulatus ticks isolated from a red deer in Southern Belgium (Wirtgen et al., 2011).

The occurrence of indigenous cases of canine (Losson et al., 1999) and equine (Mantran et al., 2004) babesiosis in Belgium during the last two decades suggests that this tick species could be indigenous 
in this country. The present work was carried out to investigate its presence in different locations in Belgium. In addition, to determine potential vectorial capacity, a specific PCR test was applied to check for the presence of Babesia spp. in the collected material.

\section{Material and methods}

\section{Tick collection sites}

Four locations were identified in Belgium where D. reticulatus ticks were suspected to be present, namely Beveren (further referred to as location 1) and Moen (location 2) in the northern part of Belgium, Mons (location 3) and Martilly (location 4) in the southern part of Belgium (Figure 1). The Beveren site (location 1, province of East-Flanders) was identified in 2009 when D. reticulatus ticks were found repeatedly on a domestic dog that had no history of traveling abroad. The site is suburban, and was established about a decade ago. It is a marshy area with a shallow artificial basin in the middle of the site. It is currently in use as a natural water purification area with an additional function as flood basin in times of heavy rain. It is situated between a railroad track and a provincial road and is often used as recreational area for dogs. The marshy area consists of a mixture of grasses. The dryer patches are occupied mainly by hornbeam and blackberry.

The site in Moen (location 2, province of West Flanders) was selected on the basis of the posting of photographs on an online observations site (www.waarnemingen.be) showing what appeared to be questing $D$. reticulatus ticks that had been misidentified as Ixodes ricinus ticks. The location is a natural reserve of about 26 hectares, along a canal that is accessible for recreational purposes.

Flagging on this site was not performed on a regular a basis.

Location 3 is situated in Mons (province of Hainaut) and consists of fallow land flanked by a road. This is close to a leisure area consisting of an artificial lake surrounded by a walking path extensively used for walking and exercising dogs. The vegetation consists of grass, hawthorns, blackthorns, brambles and birch trees. According to local vets this area is a focus of canine babesiosis (Losson et al., 1999).

Location 4 is situated in Martilly (province of Luxembourg) where two areas (referred to as "zone 1" and "zone 2") at about 600 meters apart from each other were monitored. Both zones are located in a 
rural environment consisting of woodland (mainly pine trees) and pastures used for cattle grazing. In zone 1 the trees were cut down a few years ago and the vegetation is now comprised of brambles, ferns, blackthorns and jennets close to a small stream. Zone 2 is a wood comprising mainly birch trees and oak trees, brambles and ferns were also present. In both zones roe deer (Capreolus capreolus) and red deer (Cervus elaphus) are present, evident by the presence of numerous faecal deposits. Both zones were selected because $D$. reticulatus were found attached to two red deer killed in these sites by poachers in February 2007.

\section{Tick collection}

Ticks were trapped by flagging with a 100 by $100 \mathrm{~cm}$ flannel cloth. Flagging was performed in dry or sufficiently dry conditions, wind speed less than $3 \mathrm{Bft}$ and between 10.00 a.m. and 3.00 p.m. Temperature on the ground ( $2 \mathrm{~cm}$ above surface) and air temperature (1.5 $\mathrm{m}$ above surface) were recorded during collection.

Location 1 was monitored on a weekly basis, from the end of February 2010 up to the third week of November. Location 2 was visited only on a few occasions. Locations 3 and 4 were sampled on a weekly basis, from March to August. Ticks were stored in 100\% ethanol immediately after trapping and morphologically identified using a standard key (Arthur, 1963). Climatic data were obtained from the Royal Meteorological Institute of Belgium (http://www.meteo.be).

\section{DNA extraction and PCR}

Tick DNA extraction was performed according to the proteinase $\mathrm{K}$ protocol $(20 \mathrm{mg} / \mathrm{ml})$ of Boom et al., (1990). To discount potential false-negative results due to polymerase chain reaction (PCR) inhibition and to validate the efficiency of the DNA extraction, an initial PCR test targeting a 325-bp DNA fragment corresponding to the tick $16 \mathrm{~S}$ rRNA gene was performed. This PCR was set up using $16 \mathrm{~S}+1$ and 16S-2 primers (Baumgarten et al., 1999). Only tick-DNA positive samples were further analyzed for the presence of Babesia spp. 
The Babesia spp. genus-specific PCR was developed according to Casati et al. (2006) using BJ1 and BN2 primers and generated amplification of a 411-452 bp fragment of the 18S rRNA gene (Lempereur et al., 2011).

\section{Statistical analysis}

Possible correlations between environmental factors (temperature and humidity) and numbers of collected ticks were investigated using the Pearson correlation test. $\mathrm{P}<0.05$ was considered to indicate a significant correlation.

\section{Results}

Two different tick species -Ixodes ricinus and D. reticulatus- were identified on all sites except the Beveren site where only D. reticulatus was trapped. A total of 282 D. reticulatus adult ticks were collected from the 4 sites (98 males, 184 females). The majority of the D. reticulatus ticks were found from early March until June with a peak in March. A few specimens were also found in July, August and October. Although Ixodes ricinus is the most prevalent tick species in Belgium, only D. reticulatus was obtained in location 1 (Beveren) with a total of 139 adult ticks collected (47 males and 92 females). The weekly number of trapped ticks indicated that questing activity was highest in March-April (Figure 2). A period of heavy rain with flooding in the last weeks of November and subsequently freezing temperatures and snow in December obliged us to halt our survey. The most relevant climatic parameters are summarized in Table 1.

No correlation was found between the air and ground temperature at the time of sampling for male, female or total number of ticks flagged, but the majority of the ticks were collected at an air temperature of approx $16^{\circ} \mathrm{C}$ and a ground temperature of $6^{\circ} \mathrm{C}$, from the second week of March up to the third week of April.

Four out of 234 available tick DNA extracts remained negative for the tick 16S rRNA gene PCR test even after diluting the samples 10 and $100 \mathrm{X}$ and were discarded. The remaining $230 \mathrm{DNA}$ extracts were all scored negative for Babesia spp using the Babesia specific PCR test. 


\section{Discussion}

D. reticulatus is known to occur in Europe but in the North of Western Europe, its distribution is considered as scarce and has not been accurately recorded. Recently, questing populations of this tick were discovered by flagging in the Netherlands (Nijhof et al., 2007). Its presence has also been documented in Germany (Dautel et al., 2006), in Poland (Zygner et al., 2009) in Austria (Sixl et al., 2003) and in the western part of Switzerland (Porchet et al., 2007). In central France it is the commonest tick present on dogs but on this host is replaced in the south of France by Rhipicephalus sanguineus and in the north by Ixodes canisuga (Hillyard, 1996). In this survey indigenous questing populations of D. reticulatus were found in Belgium. These results confirm the results of a previous survey which indicated the presence of low numbers of feeding adults of D. reticulatus on dogs in the country (Losson et al., 1999). As Belgium is situated between France and the Netherlands, it seems likely from this study and others that the species has enlarged its distribution area in recent years from Northern France to the Netherlands, invading Belgium in the process. Different factors such as landscape use and climate changes, human activities, increased host population densities (such as cervids) could explain this spreading as summarized by Dautel et al. (2006).

While the establishment of I. ricinus might take 2 or more years, due to a life cycle that can take 3-4 years to complete (Gray, 1991), the life cycle of D. reticulatus is probably shorter. The ovipositioning activity of the species in spring seems to be a determining factor for flagging success (Zahler \& Gothe, 1995). Although the year 2010 was globally the warmest year ever $\left(0.62{ }^{\circ} \mathrm{C}\right.$ above the $1901-2000$ mean) it was for Belgium a colder-than-normal year (yearly mean $9.5^{\circ} \mathrm{C}$, compared to $11.0^{\circ} \mathrm{C}$ in 2009 and $12.3{ }^{\circ} \mathrm{C}$ in 2008). Climatic and geographical differences between N-Belgium (atlantic climate, altitude on average below 50 meters) and S-Belgium (a more continental climate, altitude on average above 200 meters) are most probably responsible for the earlier questing activity in Northern Belgium. Despite the evidence for possible expansion, the study results suggest that $D$. reticulatus has a rather focal occurrence in Belgium and is localized in different fairly specific environments. The best example is, in this study, the difference of the habitat between areas. Thus, D. reticulatus was collected from rural areas with presence of deer and cattle (location 4) or cattle and horses (location 2) 
but was also located in sub-urban environments used for leisure activities and accessible to walkers and dogs (locations 1 and 3). It may be noteworthy that all the positive sites are fairly humid with the presence of water (marshes, river, canal, lake) nearby.

Given its vectorial capacity, spread of D. reticulatus can affect the occurrence of certain diseases. Indeed, the prevalence of $B$. canis canis in D. reticulatus was estimated to be $1 \%$ and $4 \%$ in Slovenia and Russia respectively (Duh et al., 2004) (Rar et al., 2005). A similar observation was made in the Netherlands where autochtonous canine babesiosis foci are known to exist (Matjila et al., 2005). No evidence for presence of Babesia spp. specific DNA was found in any of the tick samples analyzed. However, the possibility that $D$. reticulatus can act as a vector for B. canis canis cannot be ruled out completely given the low prevalence of tick infection and the relatively low number of ticks analyzed. In conclusion, the presence of indigenous populations of $D$. reticulatus was demonstrated for the first time in several distinct areas of Belgium. A more detailed monitoring of D. reticulatus populations and screening for Babesia canis canis and other viral, rickettsial and bacterial pathogens is warranted in future studies.

Acknowledgements: This study was made possible by grant WB28 of the Belgian Ministry of Defense. The dog survey that disclosed the D. reticulatus site in Beveren was partially financed by Bayer Health Care. Laetitia Lempereur is an Early Stage Researcher supported by the POSTICK ITN (Post-graduate training network for capacity building to control ticks and tick-borne diseases) within the FP7- PEOPLE - ITN programme (EU Grant No. 238511). We thank Prof. Brian Shiels for his critical reading of the manuscript. 


\section{References}

Arthur, DR. (1963) British Ticks. London: Butterworth \& Co.

Barutzki D., Reule M., Scheunemann R., Heile C., Schein E., (2007) Die Babesiose des Hundes Deutsches Tierärzteblatt, 3, 284-293.

Baumgarten B.U., Rollinghoff M., Bogdan C. (1999) Prevalence of Borrelia burgdorferi and granulocytic and monocytic ehrlichiae in Ixodes ricinus ticks from Southern Germany. Journal of Clinical Microbiology, 37, 3448-3451.

Boom, R., Sol C. J., Salimans M. M, Jansen C. L., Wertheim-van Dillen P. M., van der Noordaa J. (1990) Rapid and simple method for purification of nucleic acids. Journal of Clinical Microbiology, 28, 495-503.

Casati, S., Sager H., Gern L., Piffaretti J. C. (2006) Presence of potentially pathogenic Babesia sp. for human in Ixodes ricinus in Switzerland. Annals of Agricultural and Environmental Medicine, 13, 6570.

Dautel H., Dippel C., Oehme R., Hartelt K., Schettler E. (2006). Evidence for an increased geographical distribution of Dermacentor reticulatus in Germany and detection of Rickettsia sp. RpA4. International Journal of Medical Microbiology, 296, 149-156.

Duh, D., Tozon N., Petrovec M., Strasek K., Avsic-Zupanc T. (2004) Canine babesiosis in Slovenia: molecular evidence of Babesia canis canis and Babesia canis vogeli. Veterinary Research, 35, 363368.

Estrada-Pena A., Jongejan F. (1999) Ticks feeding on humans: a review of records on human biting Ixodidea with special reference to pathogen transmission. Experimental and Applied Acarology, 23, 685-715. 
Fain A. (1989) Remarques preliminaires sur les tiques (Acari: Ixodoidea) de Belgique. Symposium Invertebres de Belgiques, pp 211-217.

Fain, A. (1990) Les tiques de Belgique (Acari : Ixodidea). Van Goethem, J. eds. Documents de travail de l'Institut Royal des Sciences Naturelles de Belgique.

Gray J. S. (1991) The development and seasonal activity of the tick Ixodes ricinus: a vector of Lyme borreliosis. Revue Medical and Veterinary Entomology, 79, 323-333.

Gray J. S., Dautel H., Estrada-Pena A., Kahl O., Lindgren E. (2009) Effects of climate change on ticks and tick-borne diseases in Europe. Interdisciplinary Perspectives in Infectious Diseases, Volume 2009, Article ID 593232, 12 pages. doi:10.1155/2009/593232.

Heile C., Heydorn A.-O., Schein E. (2006) Dermacentor reticulatus (Fabricius, 1794) - Verbreitung, biologie und vektor von Babesia canis in Deutschland. Berliner und Münchener Tierärztliche Wochenschrift, 119, 330-334.

Hillyard, P. D. (1996) Ticks of North-West Europe. The Natural History Museum, London.

Kahl, O., Janetzki C., Gray J. S., Stein J., Bauch R. J. (1992) Tick infection rates with Borrelia: Ixodes ricinus versus Haemaphysalis concinna and Dermacentor reticulatus in two locations in eastern Germany. Medical and Veterinary Entomology, 6, 363-366.

Lempereur, L., De Cat A., Caron Y., Madder M., Claerebout E.,. Saegerman C. and Losson B. (2011) First molecular evidence of potentially zoonotic Babesia microti and Babesia sp. EU1 in Ixodes ricinus ticks in Belgium. Vector-Borne and Zoonotic Diseases, 11(2), 125-130

Lindgren E. and Gustafson R. (2001) Tick-borne encephalitis in Sweden and climate change. The Lancet, 358, 16-18.

Losson B., Mollet J.J., Avez F., Malaise F., Mignon B. (1999) Description de trois cas autochtones de Babésiose canine (Babesia canis) en Belgique. Annales.MédicaleVétérinaire 143, 119-124 
Losson, B, Baar, D., Marechal, F., Barbé, M., Mignon, B. Hard ticks (Acarina, Ixodidae) found on domestic carnivores in Belgium: A survey conducted during three consecutive years. (2003) Proceedings of the XIX Conference of the World Association for the Advancement of Veterinary Parasitology, New-Orleans, USA. p 239.

Mantran A., Votion D.M., Amory H. (2004) Piroplasmose: une réalité belge ? Proceedings of the annual meting of the Belgian Equine Practitioners Society, p 21.

Martinod, S. and B. Gilot. (1991) Epidemiology of canine babesiosis in relation to the activity of Dermacentor reticulatus in southern Jura (France). Experimental Applied. Acarology 11, 215-222.

Matjila TP., Nijhof AM., Taoufik A., Houwers D., Teske E., Penzhorn BL., Jongejan F. (2005) Autochtonous canine babesiosis in The Netherlands. Veterinary Pathology. 131, 23-29.

Nijhof A.M., Bodaan C., Postigo M., Nieuwenhuijs H., Opsteegh M., Franssen L., Jebbink F., Jongejan F. (2007) Ticks and associated pathogens collected from domestic animals in the Netherlands. Vector-Borne and Zoonotic Diseases, 7, 585-595.

Perez-Eid, C. (2007) Les Tiques, Identification, biologie, importance médicale et vétérinaire. Monographie de microbiologie. Tec \& Doc EMinter\& Lavoisier eds.

Porchet M. J., Sager H., Muggli L., Oppliger A., Müller N., Frey C., Gottstein B. (2007) A descriptive epidemiological study on canine babesiosis in the Lake Geneva region. Schweizer Archiv Tierheilkunde. 149, 457-465.

Rar, V. A., T. G. Maksimova, L. P. Zakharenko, S. A. Bolykhina, A. K. Dobrotvorsky, and O. V. Morozova. (2005) Babesia DNA detection in canine blood and Dermacentor reticulatus ticks in southwestern Siberia, Russia. Vector-Borne and Zoonotic Diseases, 5, 285-287.

Raoult D., Lakos A., Fenollar F., Beytout J., Brouqui P., Fournier P.E. (2002) Spotless rickettsiosis caused by Rickettsia slovaca and associated with Dermacentor ticks. Clinical Infectious Diseases, 34(10), 1331-1336. 
Raoult V.A., Maksimova T.G., Zakharenko L.P., Bolykhina S.A., Dobrotvorsky A.K., Morozova O.V. (2005) Babesia DNA detection in canine blood and Dermacentor reticulatus ticks in Southwestern Siberia, Russia. Vector-Borne and Zoonotic Diseases, 5, 285-287.

Sixl, W., Petrovec M., Marth E., Wust G., Stunzner D., Schweiger R., Avsic-Zupanc T. (2003) Investigation of Anaplasma phagocytophila infections in Ixodes ricinus and Dermacentor reticulatus ticks in Austria. Annals of the New York Academy of Sciences, 990, 94-97.

Sréter T., Széll Z., Varga I. (2005) Spatial distribution of Dermacentor reticulatus and Ixodes ricinus in Hungary: evidence for change?. Veterinary Parasitology. 128, 347- 351.

Wirtgen M., Nahayo A., Linden A., Losson B., Garigliany M., Desmecht D., Heyman P. (2011) Detection of Anaplasma phagocytophilum in Dermacentor reticulatus ticks. Veterinary Record, $\mathbf{1 6 8}$ (9), 248.

Zahler M., Gothe R.. (1995) Effect of temperature and humidity on egg hatch, moulting and longevity of larvae and nymphs of Dermacentor reticulatus (Ixodidae). Applied Parasitology, 36, 53-65.

Zygner, W., Gorski P., Wedrychowicz H. (2009) New localities of Dermacentor reticulatus tick (vector of Babesia canis canis) in central and eastern Poland. Poolish Journal of Veterinary Science, 12, 549-555. 
Fig 1. Map showing the four investigated locations in Belgium. Beveren $=$ location 1, Moen $=$ location 2, Mons $=$ location 3, Martilly $=$ location 4.

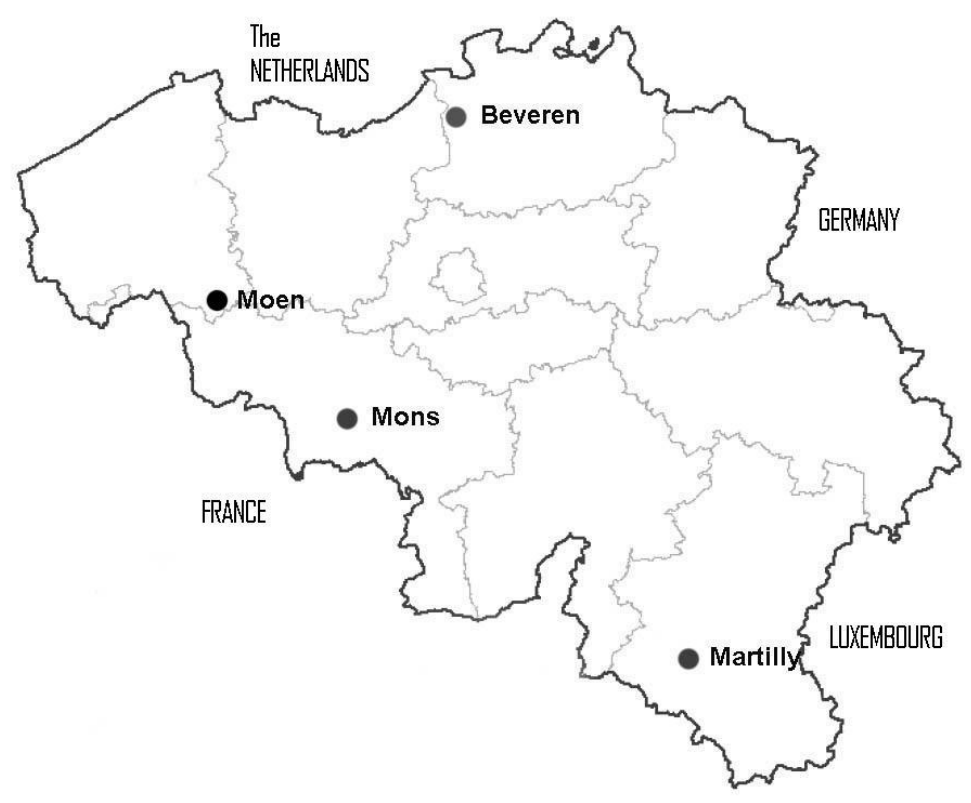


Fig 2. Number $(\mathrm{N})$ of D. reticulatus (male and female) flagged at location $1(\mathrm{~N}$ total $=139)$

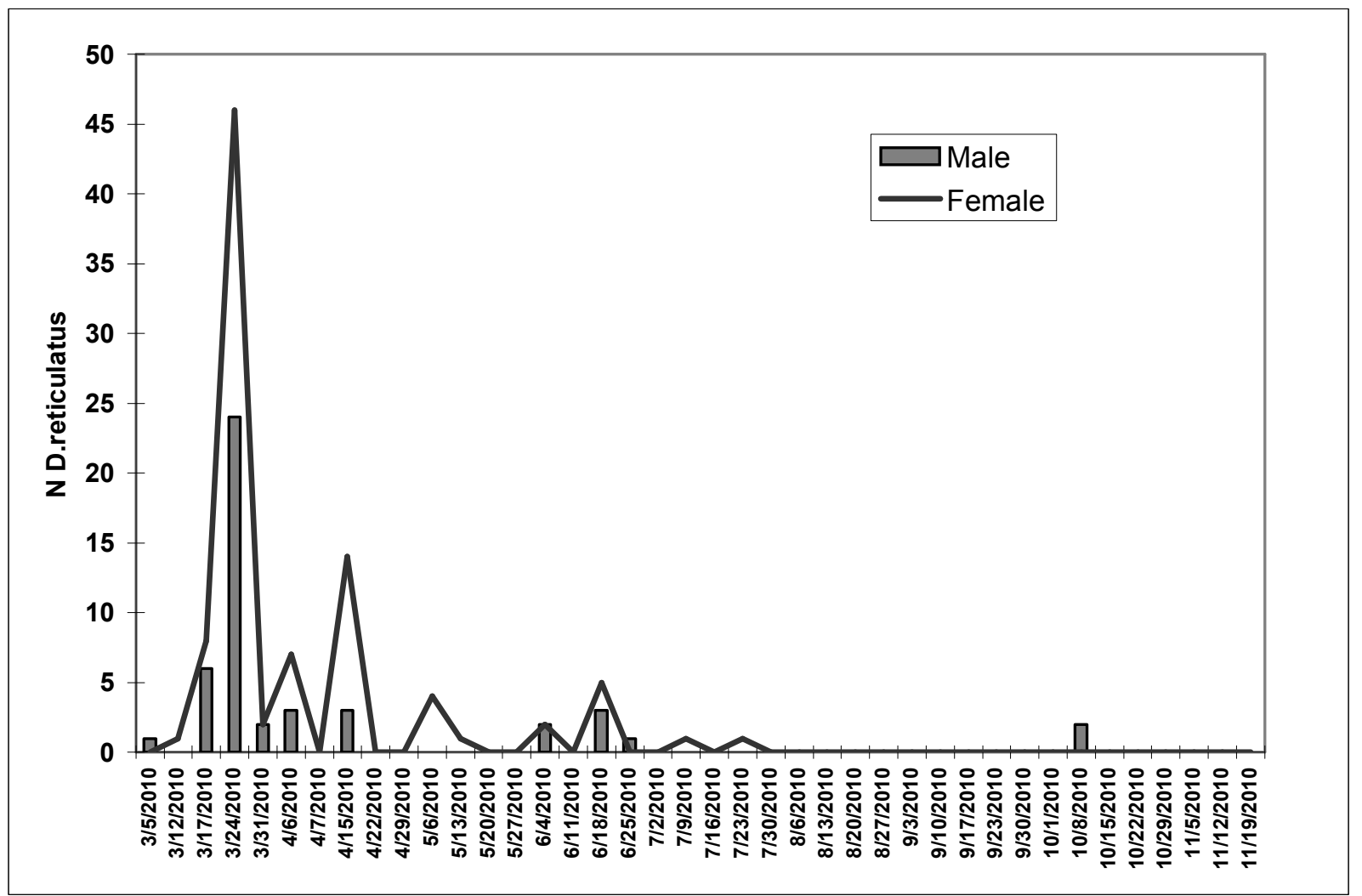


Table 1. Climatic conditions for 2010 as recorded by the Royal Meteorological Institute (http://www.meteo.be) and number of $D$. reticulatus flagged at location 1 (Beveren, East-Flanders).

\begin{tabular}{|l|c|c|c|c|c|c|c|}
\hline $\mathbf{2 0 1 0}$ & hrs sunshine & Rain days & mm rain & mean t & $\mathbf{m i n}^{\circ}$ & $\mathbf{m a x}^{\circ}$ & D. reticulatus $^{\circ}$ \\
\hline Jan & 48,7 & 18,0 & 43,9 & 0,1 & $-2,0$ & 2,2 & - \\
\hline Feb & 28,9 & 24,0 & 76,1 & 2,5 & 0,0 & 5,0 & - \\
\hline Mar & 118,0 & 13,0 & 50,2 & 6,7 & 3,1 & 10,4 & 90 \\
\hline Apr & 223,1 & 8,0 & 15,7 & 10,3 & 4,7 & 15,7 & 27 \\
\hline May & 171,8 & 14,0 & 66,6 & 11,2 & 7,0 & 15,4 & 5 \\
\hline Jun & 258,6 & 9,0 & 30,0 & 17,4 & 12,3 & 22,4 & 13 \\
\hline Jul & 252,0 & 12,0 & 62,8 & 20,5 & 15,6 & 25,8 & 2 \\
\hline Aug & 136,5 & 23,0 & 187,4 & 17,0 & 13,1 & 21,5 & 0 \\
\hline Sep & 142,6 & 18,0 & 109,8 & 14,2 & 10,2 & 18,6 & 0 \\
\hline Oct & 118,6 & 16,0 & 70,8 & 10,6 & 6,5 & 14,7 & 2 \\
\hline Nov & 23,9 & 21,0 & 124,7 & 6,1 & 4,0 & 8,2 & 0 \\
\hline Dec & 33,1 & 26,0 & 76,2 & $-0,7$ & $-3,0$ & 1,2 & - \\
\hline
\end{tabular}

